\title{
La fisiología ecológica de plantas en México
}

\author{
CARLOS VÁZQUEZ-YANES
}

Centro de Ecología, UNAM, Apdo. Postal 70-275, Delegación Coyoacán, 04510, México D. F.

\begin{abstract}
Resumen. Las investigaciones sobre la fisiología ecológica de las plantas han permitido avances notables en el conocimiento de las funciones mas básicas que afectan la distribución y abundancia de las plantas en la naturaleza. Han contribuido también al entendimiento de la forma en que la compleja interacción de los recursos del ambiente determina su crecimiento. Estos conocimientos son importantes para llegar a un buen manejo de los recursos naturales. En México esta disciplina tiene un desarrollo incipiente, aunque con algunas contribuciones de importancia.
\end{abstract}

Abstract. Research on plant physiological ecology provides tools to understand the basic functional factors determining plant abundance and distribution, and how interacting environmental resources control plant growth. This knowledge is important for the proper natural resources management. In Mexico, ecophysiology has an incipient development but some valuable contributions have been produced.

\section{INTRODUCCIÓN}

En los últimos veinte años han avanzado en forma explosiva los conocimientos científicos sobre la estructura, composición y funcionamiento de las plantas, conocimientos que habitualmente han integrado la disciplina que se conoce como fisiología vegetal. Las revistas científicas y los libros han proliferado más aceleradamente en este campo que en otros de la botánica, y los trabajos que se publican incluyen ya el nivel más fino de organización de la materia viva, incluyendo los aspectos físicos, químicos y genéticos que están detrás de cada proceso fisiológico. Para constatarlo, basta consultar algún texto general moderno de fisiología vegetal (Taiz y Zeiger, 1991), el último ejemplar del Annual Review of Plant Physiology, o algún número reciente de las revistas Plant Physiology, Planta o Physiologia Plantarum.

Como consecuencia de lo anterior y de un desarrollo comparable de la ecología, las investigaciones contenidas dentro de lo que se denomina fisiología ecológica de las plantas o ecofisiología vegetal, han alcanzado también una importancia cardinal en el proceso de entender las causas de la distribución, abundancia y cambio en las poblaciones de plantas en la naturaleza. La búsqueda de estas causas se ha dirigido al conocimiento de la plasticidad y adecuación de los procesos fisiológicos que están detrás de cada respuesta de las plantas al ambiente en el que viven, y en las interacciones que se dan entre ellas. También se pretende saber cómo es que la interacción entre diferentes recursos del ambiente controla el crecimiento de las plantas y cómo las plantas compensan exitosamente las diferencias drásticas en la disponibilidad de recursos que existen en la naturaleza (Chapin et al., 1987; Vázquez-Yanes, 1974, 1992).

Hoy en día se llega en esta búsqueda hasta el conocimiento de los mecanismos funcionales mas finos, desde el nivel organísmico hasta el molecular. El nivel funcional que los estudios ecofisiológicos cubrían en sus orígenes se restringía al organísmico, de la fisiología clásica. Por ejemplo, relaciones hídricas: absorción, presiones hidrostáticas en los tejidos y transpiración, y su conexión con la tolerancia al estrés hídrico de las plantas en condiciones de sequía. Ahora se busca ahondar más, intentando explicar el funcionamiento de los vegetales en la naturaleza, profundizando hasta el conocimiento físico-químico de las funciones, y aun llegar al conocimiento de los genes que las controlan y los aspectos evolutivos relacionados con ellos. Por ejemplo, conocer los mecanismos que desencadenan la expresión de los genes que codifican las proteínas de choque térmico, que confieren resistencia tisular a las altas temperaturas en las plantas del desierto, y determinar su heredabilidad y posible transferencia a otras plantas. Por este camino se puede llegar al trabajo interdisciplinario con la biología molecular e incluso la ingeniería genética.

Los ecofisiólogos de plantas publican sus trabajos en revistas como: Functional Ecology, Oecologia, Plant, Cell and Environment, entre otras.

\section{TEMAS DE ACTUALIDAD}

Numerosos investigadores intentan resolver incógnitas como las siguientes.

Mecanismos de adquisición de recursos del medio externo, y sus variaciones frente a la distribución heterogénea de éstos en el ambiente

Muchas investigaciones se han orientado a entender cómo enfrentan las plantas niveles muy distintos de energía luminosa disponible, humedad, concentración y composición química del nitrógeno, y de otros elementos nutricionales del suelo, y entender cómo se modifican los mecanismos fisiológicos que permiten obtener esos recursos, así como su nivel de plasticidad. Algunos estudios se han abocado al funcionamiento de las plantas y las respuestas ecológicas resultantes de éstas, que se dan en los ambientes heterogé- 
neos complejos, en el espacio y en el tiempo, que existen en comunidades muy diversas como las selvas tropicales (Medina et al., 1984).

\section{Mecanismos de resistencia al estrés ambiental de cualquier naturaleza}

Casi en cualquier lugar existe algún factor ambiental o recurso indispensable, cuyo nivel o concentración se encuentra cercano a los límites de tolerancia de las plantas, ya sea por exceso o por carencia. Así, aquí quedan englobadas las investigaciones que se refieren a la tolerancia de las plantas a las temperaturas extremas, los terrenos inundables, los suelos hipersalinos o cargados de iones de metales pesados, etc. (Alscher y Cumming, 1990).

\section{La termodinámica de las funciones de las plantas}

Este tipo de temas trata sobre la relación que existe entre las ganancias de energía y recursos del medio y su inversión en gasto respiratorio, crecimiento, desarrollo, cambio fenológico y reproducción, frente a diferentes ambientes y presiones de selección natural. En esencia, se trata de entender las causas fundamentales de las diferencias en la asignación de energía y recursos a diferentes funciones que encontramos entre los vegetales (Nobel, 1991).

\section{Variaciones y características ecológicas de procesos fisiológicos fundamentales}

Por ejemplo, las variaciones del proceso de la fotosíntesis entre epífitas, cactáceas, gramíneas y árboles, o diferencias en los mecanismos de asimilación del nitrógeno por parte de las plantas nitrófilas o las amoniófilas.

\section{Funcionamiento de las plantas frente al cambio ambiental}

Hoy en día gran número de investigadores intentan conocer el desempeño de las plantas de diversas filogenias y formas de vida, frente a las condiciones climáticas y de composición atmosférica que existirán en el futuro (niveles de $\mathrm{CO} 2$ y ozono), si los modelos atmosféricos y climáticos que predicen cambios en estos parámetros están en lo cierto (Chapin et al., 1993; Solomon y Shugart, 1993).

Los últimos diez años se han caracterizado por el desarrollo de numerosos equipos que pueden utilizarse para medir con gran precisión tanto parámetros ambientales del medio en que las plantas viven, como el desarrollo de los procesos fisiológicos -la fotosíntesis o la transpiración- que involucran un intercambio gaseoso entre la planta y la atmósfera. No está lejano el día en que sea posible también medir los intercambios hídricos y de sustancias químicas en la interfase raíz suelo con la misma precisión (Pearcy et al., 1991). Actualmente varias empresas producen equipos comerciales de medición para estudios ecofisiológicos cuyo nivel de sofisticación hubiera sido impensable sólo diez o quince años atrás.
Con respecto a los estudios en condiciones controladas, las cámaras de crecimiento han alcanzado un nivel de precisión nunca antes imaginado, pues al estar provistas de memoria digital y microprocesadores, pueden producir innumerables combinaciones de factores ambientales como luz, temperatura y humedad en un número mucho mayor de cambios por unidad de tiempo de los que era posible obtener con equipos controlados mecánicamente.

\section{LA ECOFISIOLOGÍA EN MÉXICO}

En México la ecofisiología tiene un desarrollo incipiente, cuyo inicio se remonta no más allá de dos décadas. Anteriormente existieron trabajos aislados en los que sin haberse empleado el término 'ecofisiología', o alguno equivalente, la orientación de estos tenía ese enfoque. Por ejemplo, estudios sobre la orientación de los cladodios del nopal, su calentamiento por el sol y la orientación predominante de estas plantas en el campo (Vázquez-Yanes, en prensa).

Actualmente existe en México un pequeño número de científicos que trabajan en temas de fisiología ecológica de plantas, así como algunos estudiantes en proceso de formación tanto en el país como en el extranjero. Sin embargo, se trata aun de un número muy pequeño, si lo confrontamos con las necesidades de entender diferentes aspectos de la ecología, de la complejidad y diversidad de la flora y la vegetación de México, y de los ambientes en que se desarrolla. En los aspectos aplicados a la agricultura, la forestería y la ganadería, la actividad de los ecofisiólogos podría ser fundamental para lograr el incremento en la productividad y la disminución del deterioro ecológico. Un ecofisiólogo bien entrenado estaría en capacidad de determinar con mucha precisión niveles de riego adecuados al gasto transpiratorio óptimo de las plantas y la cantidad y composición de los fertilizantes, entre otras actividades relacionadas con la agricultura. También podría colaborar en la selección y desarrollo de cultivares que utilizan en forma adecuada recursos limitados, mejorar la composición de materia nitrogenada en los forrajes y diseñar sistemas de explotación forestal que permitan las mejores condiciones de regeneración de los árboles del bosque (Lerch y VázquezYanes, 1978-1979). Estas actividades actualmente se basan en recetarios simplistas, sin una base de investigación profunda que está orientada a los diferentes ambientes y condiciones muy peculiares, característicos de un país geográficamente tan complejo como México.

De la riquísima flora mexicana, un número insignificante de plantas de especies y comunidades vegetales ha sido objeto de estudios profundos. A pesar de ésto, se da el caso de que posiblemente ningún otro grupo de plantas del cinturón intertropical del mundohayasidoobjetode estudios ecofisiológicos tan detallados como el género Piper en Los Tuxtlas, Veracruz (Field y Vázquez-Yanes,1993). Entre estas investigaciones se encuentran: mecanismos de germinación, establecimiento de plántulas, relaciones hídricas, tasas fotosintéticas, relación entre fotosíntesis, asignación de recursos y fenología, metabo- 
lismo del nitrógeno y productividad, arquitectura funcional y asociaciones micorrícicas. Todo ello persigue el objetivo de entender las causas de la distribución y abundancia de un conjuntoheteromorfode especies deestegénerofilogenéticamente natural, en el ambiente heterogéneo de una selva tropical perturbada (Vázquez-Yanes, 1991).

A pesar del incipiente desarrollo de la ecofisiología en México, ha recibido reconocimientos valiosos a nivel internacional, por ejemplo, la participación de mexicanos al menos con un capítulo en la prestigiosa serie de Academic Press, «Ecophysiological Studies Series «(Vázquez-Yanes y Orozco Segovia, 1994).

También se han llevado a cabo en México varios importantes eventos: una reunión internacional lamada: «Simposio y Taller Internacional sobre «Fisiología Ecológica de Plantas de la Selva Tropical Húmeda», que tuvo lugar en el Centro Vacacional de Oaxtepec, Morelos y en la Estación de Biología Tropical de «Los Tuxtlas», Ver. del 29 de junio al 8 de julio de 1983 (Medina et al., 1983), y dos Simposios de Ecofisiología en el IX y X Congreso Mexicano de Botánica (Vázquez-Yanes, 1992). En 1991, el Centro de Investigación Científica de Yucatán (CICY) organizó un curso y taller internacional sobre ecofisiología.

Las condiciones existen para un desarrollo sostenido de esta disciplina científica tan importante.

\section{AGRADECIMIENTOS}

Al Dr. F. A. Bazzaz por las instalaciones y facilidades operativas proporcionadas durante la estancia en la Universidad de Harvard, así como por el beneficio de sus valiosos conocimientos sobre las plantas. Este trabajo fue escrito cuando el autor era «Charles Bullard Fellow» (Harvard Forest) en la Universidad de Harvard, EUA.

\section{LITERATURA CITADA}

Alscher RG, Cumming R, edrs. 1990. Stress responses in plants: Adaptation and acclimation mechanisms. Wiley-Liss, New York.
Chapin III FS, Bloom AJ, Field CB, Waring RH. 1987. Plant responses to multiple environmental factors. BioScience 37: 49-57.

Chapin III FS, Rincón E, Huante P. 1993. Environmental responses of plants and ecosystems as predictors of the impact of global change. J. Biosci. 18: 515-524.

Field CB, Vázquez-Yanes C. 1993. Species of the genus Piper provide a model to study how plants can grow in different kinds of rainforest habitats. Interciencia 18: 230-236.

Lerch G, Vázquez-Yanes C. 1978-1979. Importancia de las investigaciones en ecofisiología vegetal como una contribución para incrementar la productividad en la agricultura tropical. Biología (C. N. E. B. México) 8-9: 12-18, 11-19.

Medina E, Mooney HA, Vázquez-Yanes C. 1983. La fisiología ecológica de las plantas de los trópicos húmedos. Ciencia (A.I.C.) 35: 191-201.

Medina E, Mooney HA Vázquez-Yanes C, edrs. 1984. Physiological ecology of plantas of the wet tropics. Task for vegetation Science 12.Dr. W. Junk Publishers, The Hague, The Netherlands.

Nobel PS.1991. Physicochemical and environmental plant physiology. Academic Press, San Diego, California.

Pearcy RW, Ehleringer J, Mooney HA, Rundel PW, edrs. 1991. Plant physiological ecology: Field methods and instrumentation. Chapman \& Hall, London.

Solomon AM, Shugart HH, edrs. 1993. Vegetation dynamics and global change. Chapman \& Hall, London.

Taiz L, Zeigler E. 1991. Plant physiology. Benjamin Cummings, Redwood City, California.

Vázquez-Yanes C. 1974. ¿Qué es la ecofisiología vegetal? Biología (C. N. E. B., México) 4: 106-108.

Vázquez-Yanes C. 1989. La fisiología ecológica de plantas. Bol. Soc. Bot. México 49: 3-5.

Vázquez-Yanes C. 1991. Cómo viven las plantas en la selva tropical, una interpretación desde el punto de vista de la fisiología ecológica. Ciencia y Desarrollo 17: 90-101.

Vázquez-Yanes C. 1992. La fisiología ecológica de plantas. Ciencias, Número Especial 5: 63-68.

Vázquez-Yanes C, Orozco-Segovia A. 1994. Signals for seeds to sense and response to gaps. En: Caldwell M, Pearcy R, edrs. Exploitation of environmental heterogeneity by plants: Ecophysiological processes above and below ground. Academic Press, New York, 261-318. 